CARPATHIAN JOURNAL OF FOOD SCIENCE AND TECHNOLOGY

journalhomepage:http://chimie-biologie.ubm.ro/carpathian_journal/index.html

\title{
DEVELOPMENT AND OPTIMIZATION OF AN OZONE FOOD PRESERVATION SYSTEM USING RESPONSE SURFACE MODELLING (RSM)
}

\author{
Said Nemmich ${ }^{1}$, Kamel Nassour ${ }^{2}$, Nadia Ramdani ${ }^{1}$, Yassine Bellebna ${ }^{1}$, Fodil Boukhoulda ${ }^{3}$, Amar \\ Tilmatine ${ }^{1}$
}

${ }^{1}$ APELEC Laboratory, Djillali Liabes University of Sidi Bel-Abbes, Algeria

${ }^{2}$ ICEPS Laboratory, Djillali Liabes University of Sidi Bel-Abbes, Algeria

${ }^{3}$ IRECOM Laboratory, Djillali Liabes University of Sidi Bel-Abbes, Algeria

*amar.tilmatine@univ-sba.dz

https://doi.org/10.34302/crpjfst/2021.13.4.4

\begin{tabular}{|c|c|}
\hline ory: & ABSTRACT \\
\hline $\begin{array}{l}\text { Received: } \\
\text { 17 June } 2020\end{array}$ & \multirow{7}{*}{$\begin{array}{l}\text { This paper is aimed to design and implement an ozone food preservation } \\
\text { system to increase the shelf life of food products. An experimental procedure } \\
\text { based on response surface modeling has been proposed in order to optimize } \\
\text { the geometrical dimensions of a planar surface dielectric barrier discharge } \\
\text { ozone generator, with minimum energy consumption. The experiments were } \\
\text { conducted in an ozone-treated cold room using green pepper, strawberries } \\
\text { and sardines. A comparative analysis using a similar untreated control room } \\
\text { has shown that such a system improves significantly the shelf life of the } \\
\text { products for long-term storage. }\end{array}$} \\
\hline $\begin{array}{l}\text { 1/ June } 2020 \\
\text { Accepted: }\end{array}$ & \\
\hline ber 2021 & \\
\hline Keywords: & \\
\hline $\begin{array}{l}\text { Ozone; } \\
\text { Surface discharge: }\end{array}$ & \\
\hline Food sto & \\
\hline & \\
\hline
\end{tabular}

\section{Introduction}

Ozone has been harnessed for beneficial purposes such as purification of drinking water, deep treatment of waste water, bleaching, deodorization, aquaculture, medicine and so on because of its strong oxidative potential (Rakovsky, et al., 2009; Nogales et al., 2008; Ramdani et al., 2016; Nemmich, et al., 2015). It is capable of inactivating bacteria, bacterial spores, molds, yeasts, protozoan cysts and viruses (Giese and Christenser, 1954; Scott and Lesher, 1963; Kim, 1998). Ozone has been tested on nearly every type of food during storage and processing to improve the safety and to extend the shelf-life of these products (Jbilou, et al ,2018; Nehari, et al., 2019). Ozone not only inactivates microbial contaminants, but is also potentially useful in decreasing the level of pesticides, such as azinphosmethyl, captan, formethanate-HC1 and ethylenethiourea, on fresh produce (Ong et al., 1996).
The food industry is interested considerably in using ozone to enhance the shelf-life and safety of food products and in exploring new applications of the sanitizer. Ozone is currently used in many countries and its use in food processing has been approved recently in the United States (Federal Register, 2001). Additionally, ozone-treated produce has just been introduced in the United States market.

The use of ozone in the food industry has been applied to shelf-life extension of commodities during storage. Recently, there has been a renewed interest in ozone and its application in food processing. Application of ozone for washing fruits and vegetables with ozone is gradually gaining acceptance.

Ozone can be produced by electric discharge, photochemical, chemical, thermal, chemonuclear, and electrolytic methods (Nassour et al., 2018; Horvath et al., 1985). The dielectric barrier discharge (DBD) method is commonly used to produce large amounts of 
ozone. The DBD produces ozone when a high voltage alternating current is applied across a discharge gap in the presence of oxygen or air (Kim et al., 2003; Moon et al., 2007; Boonduang et al., 2012).

Ozone generators have been widely studied for optimizing the output generation rate of ozone, according to several parameters such as the high voltage level, the oxygen rate, the frequency of the voltage and other factors. However, no experimental study was performed to identify the optimal geometrical sizes of an ozone generator, i.e. the dimensions of the interelectrodes gap and the effective length of the generator, giving the highest ozone concentration level with the smallest power consumption.

The aim of the present work is to propose an experimental procedure based on response surface modeling (RSM) for the identification of the optimal values of a surface DBD ozone generator used in food storage cold rooms, based on ozone generation output and power consumption (Taguchi 1987).

\section{Materials and methods}

\subsection{Ozone generator}

The most efficient method for generating ozone is to pass oxygen $\left(\mathrm{O}_{2}\right)$ through DBDplasma, which converts it into ozone, a molecule with 3 oxygen atoms $\left(\mathrm{O}_{3}\right)$.

A planar surface DBD reactor was developed, comprising a dielectric barrier made


(Figure1). The electrodes are made of aluminum adhesive strip placed on both sides of the Bakelite plate.

The high voltage electrode consists of several strips of dimensions $170 \times 2 \mathrm{~mm}^{2}$ while the ground electrode is an aluminum strip bonded to the other face of dimensions 170x160 $\mathrm{mm}^{2}$.

Several active high-voltage electrodes have been made on the top side so that their number could vary from 2 to 14 and the distance "d" between adjacent electrodes could take 5 different values $(2,4,6,8$ and $10 \mathrm{~mm})$.

The experimental laboratory setup used for the experiments is described in figure 2 . It consists of a cold chamber with adjustable temperature from 2 to $10{ }^{\circ} \mathrm{C}$ (refrigerator) of a volume equal to $0.5 \mathrm{~m} 3$.

The surface DBD ozone generator is fixed on the upper wall of the enclosure, powered by a high-voltage high-frequency power supply ( 5 $\mathrm{kV}, 100 \mathrm{~mA}, 22 \mathrm{kHz}$ ) placed outside the enclosure. A portable ozone analyzer $\left(\mathrm{O}_{3}\right.$ Technologies) was used to measure the ozone concentration produced in the chamber in ppm.

The applied voltage $U$ was measured with a digital scope (GWINSTEK GDS-3154) using a high voltage probe (Tektonix P6015A), while the current I was measured by a current probe. Moreover, the consumed power of the ozone generator was estimated by calculating the average value of the product U*I over 25000 points.

A list of values of voltage $U$ and current $I$ is provided by the scope and then the power is estimated by calculating the average value of the product $\mathrm{U}^{*} \mathrm{I}$.

For the experiments of food storage, three different food products were tested: strawberry, green pepper and sardine. Notice that one product at once was placed in the storage room and analyzed separately, in both treated and untreated enclosures.

All the experiments were performed under stable conditions of temperature $\left(5^{\circ} \mathrm{C}\right)$ and humidity $(85 \%)$ inside the storage room. 


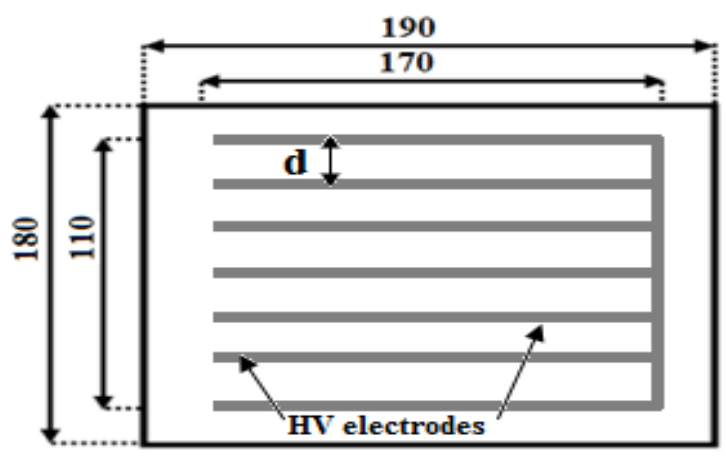

(a)

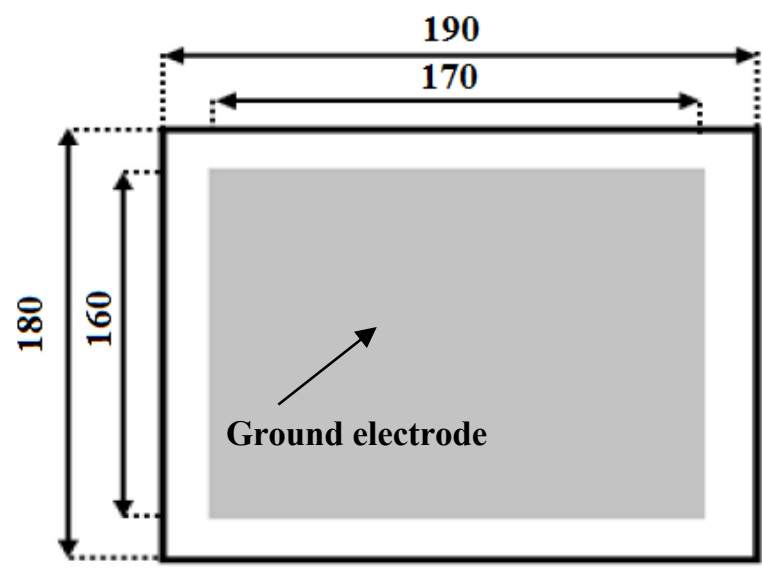

(b)

Figure 1. Surface dielectric barrier discharge ozone generator used in this study. Top (a) and bottom (b) view of the flat ozone generator (all dimensions in $\mathrm{mm}$ )

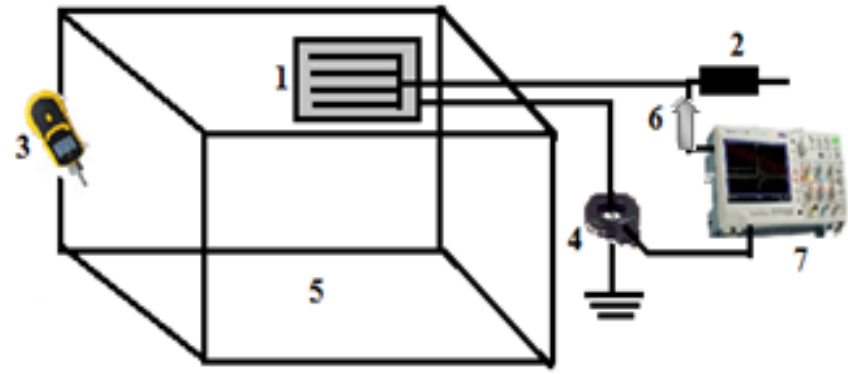

Figure 2. Descriptive schematic of the ozone air treatment system

1. Ozone Generator, 2. High-voltage transformer, 3. Ozone monitor, 4. Current probe, 5. Cold room (fridge), 6. High voltage probe,7. Digital oscilloscope.

\subsection{Experimental Designs Methodology}

Methodology of the experimental designs makes it possible to determine the number of experiments to be achieved according to a welldefined objective, to study several factors simultaneously, to reduce dispersion related to measurements, to appreciate the effects of coupling between factors and finally to evaluate the respective influence of the factors and their interactions (Frigon, 1996; Taguchi, 1987; Eriksson, 2000). 
Before starting the experiments, it is necessary to set the best and suitable design which can model the process with the most possible precision. In this paper, the Composite Centred Faces design (CCF), which gives quadratic models, was adopted. It is possible to determine a quadratic dependence between the output function to optimize (response) and the input variables $\mathrm{u}_{\mathrm{i}}(\mathrm{i}=1, \ldots, \mathrm{k})$ (factors):

$$
\begin{aligned}
y=f\left(u_{i}\right) & =c_{0}+\sum c_{i} u_{i}+\sum c_{i j} u_{i} u_{j} \\
& +\sum c_{i i} u_{i}^{2}
\end{aligned}
$$

Knowing that $\Delta \mathrm{u}_{\mathrm{i}}$ and $\mathrm{u}_{\mathrm{i} 0}$ are respectively the step of variation and the central value of factor $i$, reduced centred values of input factors may be defined by the following relation:

$$
\mathrm{x}_{\mathrm{i}}=\left(\mathrm{u}_{\mathrm{i}}-\mathrm{u}_{\mathrm{i} 0}\right) / \Delta \mathrm{u}_{\mathrm{i}}
$$

With these new variables, the output function becomes:

$$
\begin{aligned}
y=f\left(x_{i}\right) & =a_{0}+\sum a_{i} x_{i}+\sum a_{i j} x_{i} x_{j} \\
& +\sum a_{i i} x_{i}^{2}
\end{aligned}
$$

The coefficients can be calculated or estimated by a data-processing program, in such a way to have a minimum variance between the predictive mathematical model and the experimental results.

MODDE 5.0 software (Umetrics AB, Umea, Sweden) was used, which is a Windows program for the creation and the evaluation of experimental designs [MODDE 5.0, 1999]. The program assists the user for interpretation of the results and prediction of the responses. It calculates the coefficients of the mathematical model and identifies best adjustments of the factors for optimizing the process. Moreover, the program calculates two significant statistical criteria which make it possible to validate or not the mathematical model, symbolized by $\mathrm{R}^{2}$ and $\mathrm{Q}^{2}$. The former is called the goodness of fit, and is a measure of how well the model can be made to fit the raw data; it varies between 0 and 1 , where 1 indicates a perfect model and 0 no model at all. The latter is called goodness of prediction, and estimates the predictive power of the model. LikeR ${ }^{2}, \mathrm{Q}^{2}$ has the upper bound 1 , but its lower limit is minus infinity. For a model to pass the diagnostic test, both parameters should be high, and preferably not separated by more than $0.2-0.3$.

\section{Results and discussions}

The experimental study was carried out by considering the two most important factors of a surface DBD ozone generator, which are the number $\mathrm{N}$ of high voltage electrode-wires and the distance between wires $\mathrm{d}(\mathrm{in} \mathrm{mm}$ ).

Design of experiments methodology is useful for screening and optimization. Screening experiments are designed here to identify the domain of variation of two factors, classical "one-factor-at-a-time" experiments. The optimization stage of an experimental procedure should enable the determination of factor values for which the consumed power is a minimum. In addition, several studies have shown that typical ozone concentrations used for food processing in cold rooms should be in the range between 2 and 7 ppm (particles per million) (Rice, Rip G., et al, 1997; Hampson, Brian C., et al 1997).

Therefore, we estimated the operating time $\Delta \mathrm{t}$ of the ozone generator to ensure an ozone concentration between 2 and $7 \mathrm{ppm}$ and also the power consumed by the generator according to factors $\mathrm{d}$ and $\mathrm{N}$.

\subsection{Screening experiments}

The variation limits of number of wires $\mathrm{N}$ and distance dare defined by following "onefactor-at-a-time" experiments.

- Experiment 1: Variable number of wires $\mathrm{N}(4-14)$, with a constant value of wires distance $\mathrm{d}=10 \mathrm{~mm}$.

- Experiment 2: Variable distance d (2-10 $\mathrm{mm}$ ) with a constant value of the number of wires $\mathrm{N}=6$.

Obtained results of above experiments are given in figures 3 and 4 . The operating time $\Delta t$ to 
achieve an ozone concentration range $2-7 \mathrm{ppm}$ and the consumed power were considered as significant for the evaluation of the process and represented as function of the two-control factor. The domain of variation of $\mathrm{N}$ and $\mathrm{d}$ were then defined based on results obtain in the previous section. The variation domain for each factor was determined as follows:
- Number of wires: $\mathrm{N}_{\min }=8 ; \mathrm{N}_{\max }=12$;

- Distance between wires: $\mathrm{d}_{\min }=6 \mathrm{~mm}$; $\mathrm{d}_{\max }=10 \mathrm{~mm}$.

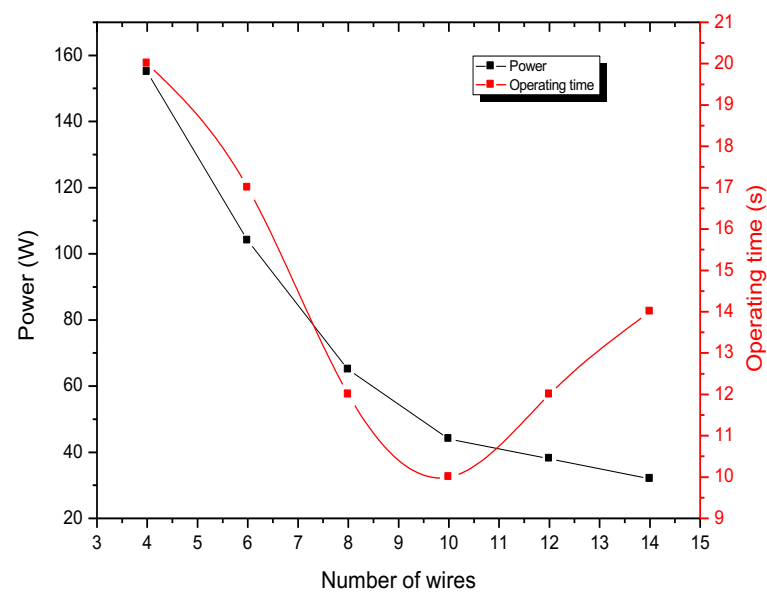

Figure 3. Variation of time $\Delta \mathrm{t}$ and power $\mathrm{P}$ as function of the number of wires $(\mathrm{d}=10 \mathrm{~mm})$



Figure 4. Variation of the operating time $\Delta \mathrm{t}$ and the power $\mathrm{P}$ as function of the distance $\mathrm{d}$ between wires $(\mathrm{N}=6)$

\subsection{Set Point Identification}

The identification of the optimal values of both factors were determined by using a central CCF design; the two levels "max" and "min" are the limits established in previous section for each of the two variables, $\left(\mathrm{N}_{\min }, \mathrm{N}_{\max }\right)$ and $\left(\mathrm{d}_{\min }\right.$, $\left.\mathrm{d}_{\max }\right)$. The central point $\left(\mathrm{N}_{\mathrm{c}}\right.$ and $\left.\mathrm{d}_{\mathrm{c}}\right)$ being calculated as follows:

$$
\begin{aligned}
& N c=\left(N_{\min }+N_{\max }\right) / 2=10 \\
& D_{c}=\left(d_{\min }+d_{\max }\right) / 2=8 \mathrm{~mm}
\end{aligned}
$$


The experimental results of the CCF design are given in Table I. Besides the operating time
$\Delta \mathrm{t}$, the power $\mathrm{P}(\mathrm{W})$, was also considered as a significant response and reported in the table 1.

Table 1. Results of the CCF design

\begin{tabular}{|c|c|c|c|c|}
\hline Exp. & $\begin{array}{c}\text { Number of } \\
\text { wires N }\end{array}$ & $\begin{array}{c}\text { Distance } \\
\mathbf{d}(\mathbf{m m})\end{array}$ & $\begin{array}{c}\text { Operating time } \\
\Delta \mathbf{t}(\mathbf{s})\end{array}$ & $\begin{array}{c}\text { Power } \\
\mathbf{P}(\mathbf{w})\end{array}$ \\
\hline 1 & 8 & 6 & 12 & 65 \\
\hline 2 & 12 & 6 & 12 & 38 \\
\hline 3 & 8 & 10 & 12 & 65,6 \\
\hline 4 & 12 & 10 & 12 & 45,3 \\
\hline 5 & 8 & 8 & 15 & 91,5 \\
\hline 6 & 12 & 8 & 15 & 58,4 \\
\hline 7 & 10 & 6 & 10 & 44 \\
\hline 8 & 10 & 10 & 10 & 44,8 \\
\hline 9 & 10 & 8 & 13 & 67,1 \\
\hline 10 & 10 & 8 & 12,5 & 67,1 \\
\hline 11 & 10 & 8 & 12 & 67,1 \\
\hline
\end{tabular}

The mathematical models of time operating $\Delta t$ and Power P were obtained with MODDE 5.0 and plotted as shown in figures 5 and 6 . Since the statistical criteria $\mathrm{R}^{2}$ and $\mathrm{Q}^{2}$ were close to the unit, as noted in figures 5 and 6 , both models were validated and have been used for prediction and optimization analysis.

According to the results, we found that the effects of both factors are significant for the power and the operating temperature. Concerning the power $\mathrm{P}$, the coefficient of the number of wires $\mathrm{N}$ is negative. On the other hand, the distance does not have an important effect on the power in the studied interval, however the parameter $\mathrm{N}^{2}$ seems to have an important influence on the power.

Concerning the operating time $\Delta \mathrm{T}$ the most significant parameters are $\mathrm{N}^{* 2}$ and $\mathrm{d}^{* 2}$. Moreover, the results obtained using the mathematical models do not indicate any significant interaction between the geometric factors $\mathrm{N}$ and $\mathrm{d}$, their effect not being significant for the two responses.

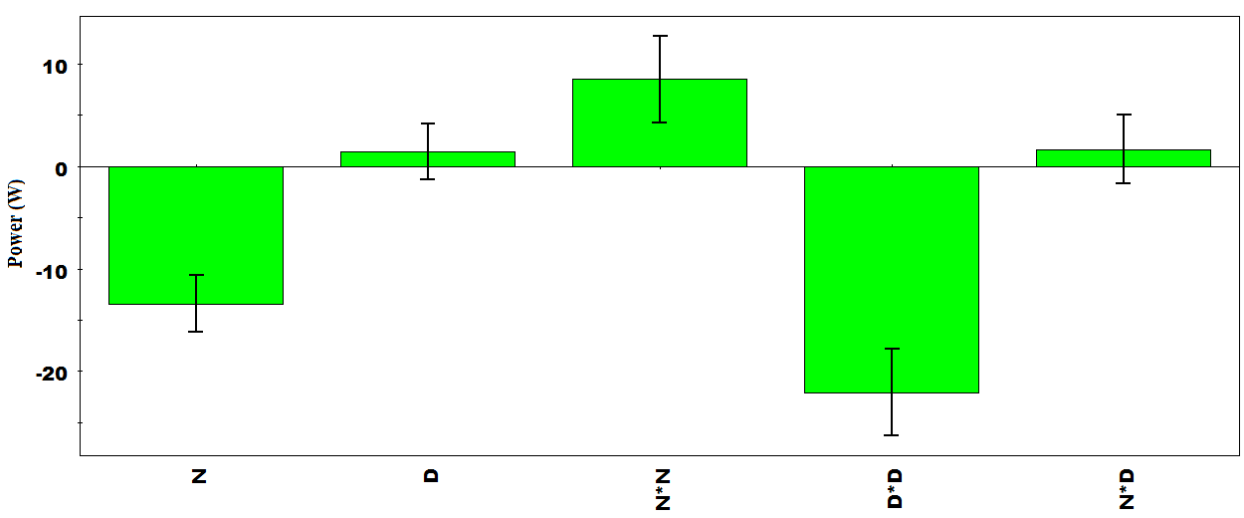

Figure 5. Plotted coefficients of the obtained models for Power (W)

$$
\left(\mathrm{R}^{2}=98 \% ; \mathrm{Q}^{2}=86 \%\right)
$$






Figure 6. Plotted coefficients of the obtained models for the operating time (s)

$$
\left(\mathbf{R}^{2}=98 \% ; \mathbf{Q}^{2}=93 \%\right)
$$

Furthermore, MODDE 5.0 includes an optimization routine that can simultaneously process multiple responses assigned by different weights. The software offers the possibility to identify the optimal values of the two factors that should minimize the power consumed and the duration of operation (Figure.7).
According to this model, the process optimum (ie, minimize power and operating temperature with an ozone concentration of $7 \mathrm{ppm}$ ) should be obtained for $\mathrm{N} \approx 11$ and $\mathrm{d}=$ $6 \mathrm{~mm}$. In figure 8 are represented the isoresponse contours obtained with the present model.

\begin{tabular}{|c|c|c|c|c|c|c|c|}
\hline & Response & Criteria & Weight & Min & Target & Max & \\
\hline 1 & Operating time $\mathrm{N}$ & Minimize $\boldsymbol{}$ & 1 & & 9.5921 & 10.0921 & \\
\hline 2 & Power & Minimize - & 1 & & 34.1576 & 39.3556 & 56 \\
\hline \multicolumn{5}{|c|}{ Iteration: 5001} & & & \\
\hline & 1 & 2 & \multicolumn{2}{|l|}{3} & 4 & 5 & 6 \\
\hline & Number of wires & Distance & \multicolumn{2}{|c|}{ Operating time } & Power & iter & $\log (D)$ \\
\hline 1 & 10.6489 & 6 & \multicolumn{2}{|c|}{10.0775} & 39.3402 & 5000 & -0.014 \\
\hline 2 & 10.6327 & 10 & \multicolumn{2}{|c|}{10.066} & 43.3775 & 5001 & 0.3058 \\
\hline 3 & 10.6626 & 6 & \multicolumn{2}{|c|}{10.0876} & 39.2749 & 5000 & -0.0107 \\
\hline 4 & 10.6323 & 10 & \multicolumn{2}{|c|}{10.0657} & 43.3789 & 5000 & 0.3058 \\
\hline 5 & 10.6237 & 10 & \multicolumn{2}{|c|}{10.0596} & 43.4064 & 5000 & 0.3054 \\
\hline 6 & 10.6626 & 6 & \multicolumn{2}{|c|}{10.0876} & 39.2749 & 5000 & -0.0107 \\
\hline 7 & 10.592 & 6 & \multicolumn{2}{|c|}{10.0381} & 39.6188 & 5000 & -0.0224 \\
\hline 8 & 10.6302 & 10 & \multicolumn{2}{|c|}{10.0642} & 43.3857 & 5000 & 0.3057 \\
\hline
\end{tabular}

Figure 7. Results of the optimization routine of MODDE 5.0 for minimization of the power and operating time 


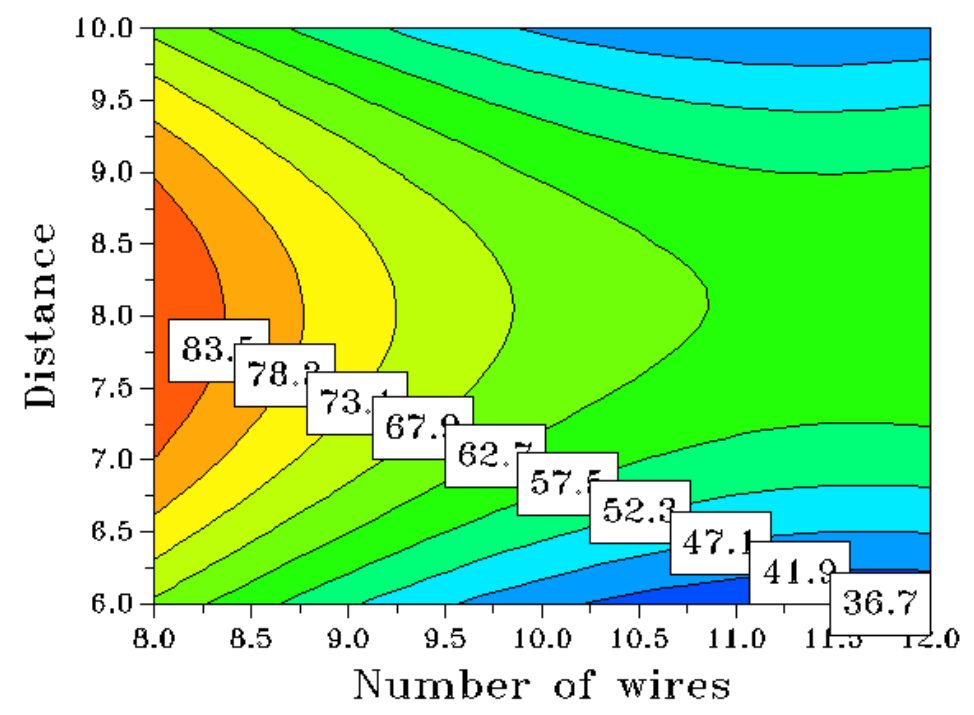

Figure 8. Response contour plots of power $\mathrm{P}$

\subsection{Food storage application}

The typical ozone concentrations typically used for the treatment in cold food storage rooms should be in the range 2-7 ppm (Graham, 1998). Consequently, a time control system has been developed using Arduino card programming to control the On /Off time periods of the ozone generator to ensure a continuous ozone concentration ranging between 2 and 7 ppm. To achieve these concentrations, preliminary tests were carried out to determine the suitable operation periods of the ozone generator.

Once the ozone generator is set On, an ozone concentration $\mathrm{C}_{\mathrm{O} 3}$ equal to $7 \mathrm{ppm}$ is quickly achieved after an operating time of $10 \mathrm{~s}$. After this period of $10 \mathrm{~s}$, the ozone generator is set Off so that the concentration will not exceed $7 \mathrm{ppm}$. In figure 9 , is plotted the decline of $\mathrm{C}_{03}$ with respect to time. Obtained results show that the duration during which the concentration decreases from 7 to $2 \mathrm{ppm}$, in the conditions of humidity and temperature of the storage room, is equal to 25 minutes. Based on these results, the time control system of the ozone generator that has been set to maintain an ozone concentration between 2 and 7 ppm, is an operating time of 10 seconds and shutdown intervals of 25 minutes.

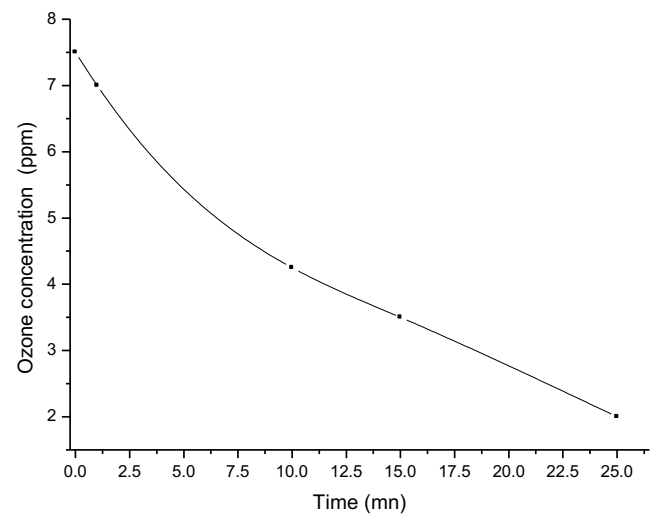

Figure 9. Decline of the ozone concentration with respect to time during the shutdown of the ozone generator 
The evolution of the food products was analyzed by visual control after several days of storage in the treated and untreated rooms. As shown in figure.10, Photographs were taken after7 days for Strawberry, 20 days for green pepper and 5 days for Sardine.

These results show clearly that foods stored in the enclosure treated with ozone are much more resistant to contamination compared to similar products placed in the untreated enclosure. Indeed, the ozone is a powerful oxidizer that has been recommended by several researchers (Liew et al, 1994; Pandiselvam et al, 2019) to reduce the decomposition of the product and prolong the storage period, by eliminating bacteria and stopping their development. Ozone also reacts with ethylene, the gas responsible for the ripening of fruits and vegetables because it causes damage and increases decomposition (Skog et al, 2001; Aziz et al, 2018). In addition, it is mentioned in several studies (Smilanick et al, 2003; Tuffi et al, 2012; Montesano et al, 2004) that the exposure of fruits and vegetables to ozone can slow the sporulation of fungi harmful to citrus fruits, especially Geotrichum and Pennicilium. Moreover, the application of ozone for sardine storage leads to significantly lower counts of aerobic mesophiles, psychrotrophic bacteria, anaerobes, coliforms, and both lipolytic and proteolytic microorganisms in sardine muscle, and of surface counts of mesophiles and psychrotrophic bacteria in sardine skin. Furthermore, a more interesting feature that was observed which consists in a less amount of mass loss for the food products stored in the ozone treated enclosure. As shown in figure.11, a mass loss up to $50 \%$ and $60 \%$ was observed for strawberry and green pepper respectively.

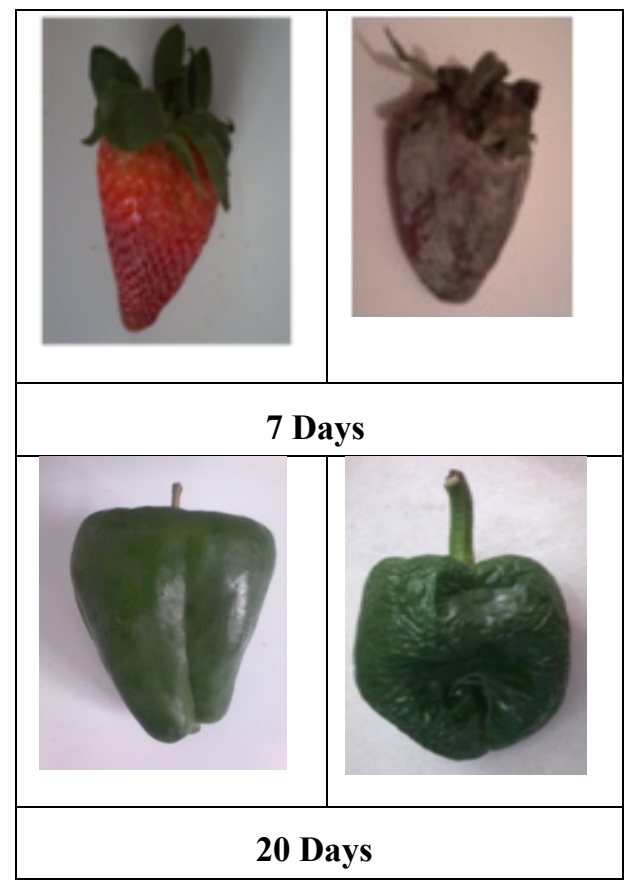




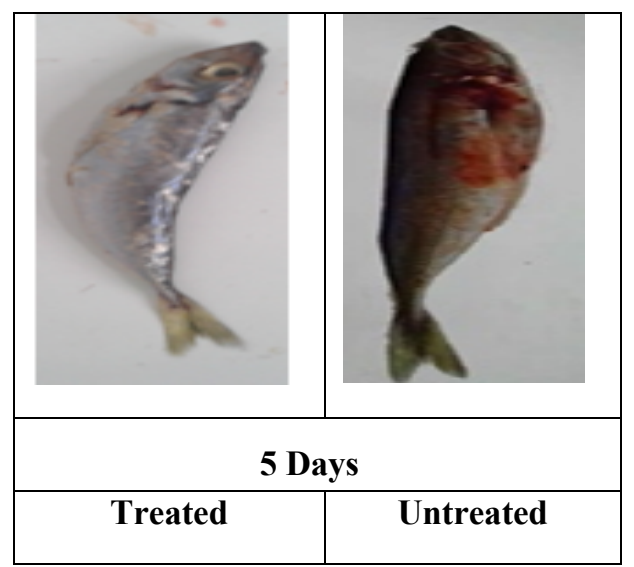

Figure 10. Comparison between the states of ozone-treated and untreated food products after several storage days



Figure 11. Mass loss of the food products after storage

\section{Conclusions}

An experimental procedure based on RSM technique was proposed for the determination of the optimal factors of the ozone generator, regarding the effects of the ozone concentration and the consumed power responses. Moreover, an ozone disinfection system for food storage was developed and analyzed for storage of Strawberry, green pepper and sardine. It was shown that food products stored in the enclosure treated with ozone are much more resistant to contamination compared to similar products placed in the untreated enclosure. Furthermore, it was observed that the weight of the ozone- treated product is greater than products stored in the untreated storage room.

\section{References}

Aziz, K. M., \& Ding, P. (2018). Ozone application in fresh fruits and vegetables. Pertanika Journal of Scholarly Research Reviews, 4(2).

Boonduang, S., Limsuwan, S., Kongsri, W. P., (2012) . Effect of Oxygen Pressure and Flow Rate on Electrical Characteristic and Ozone Concentration of a Cylinder-Cylinder DBD Ozone Generator, Limsuwan. Procedia Engineering, 32, 936 - 942.

Eriksson, L., Johansson, E., Kettaneh-Wold, N., Wikström, C., Wold, S., (2000). Design of 
Experiments., Principles and Applications, Stockholm.

Frigon, N., Mathews, D., (1996). Practical Guide to Experimental Design., $1^{\text {st }}$ Edn., Wiley, New York.

Giese, A. C., \& Christensen, E. (1954). Effects of ozone on organisms. Physiological zoology, 27(2), 101-115.

Graham, Dee M., "Use of Ozone for Food processing," Food Technology June, 1997, $51(6)$ pp. $72-75$.

Hampson, Brian C., steven.R, Friori., Application of Ozone in Food processing Operations, Same conference proceedings as ref. 1, 261-267.

Horvath, M., Bilitzky, L., \& Huettner, J. (1985). Production by chemonuclear methods. In Ozone.

Jbilou, M., Brahami, M. N., Nemmich, S., Brahami, M., \& Tilmatine, A. (2018). Ozone Food Storage Supplied by photovoltaic energy. Carpathian Journal of Food Science \& Technology, 10(4), 129-134.

Kim, J. G. (1998). Ozone as an antimicrobial agent in minimally processed foods. The Ohio State University.

Kim, J. G., Yousef, A. E., \& Khadre, M. A. (2003). Ozone and its current and future application in the food industry.

Liew, C. L., Prange, R. K. (1994). Effect of ozone and storage temperature on postharvest diseases and physiology of carrots (Daucus carota L.). Journal of the American Society for Horticultural Science.119(3), 563-567.

MODDE 5.0, 1999. User guide and tutorial., Umetrics.

Montesano, D., Somma, A., Ferrara, L. (2004). Ozone in post-harvest treatment of fruits and vegetables. Italus Hortus (Italy).

Moon, J., Jung, J., (2007). Effective corona discharge and ozone generation from a wireplate discharge system with a slit dielectric barrier. Journal of Electrostatic, 65,660666.

Nassour, K., Brahami, M., Tilmatine, A., Nemmich, S., Miloua, F., Ramdani, N., Zouzou,N., (2018). Comparative experimental analysis of ozone generation between surface and volume DBD Generators. IEEE Transactions on Dielectrics and Electrical Insulation, 25 ( 2), 428-434.

Nehari, L., Brahami, M., Bousmaha, I. S., Labair, H., Boudjella, F. Z., \& Tilmatine, A. (2019). Carpathian Journal of Food Science \& Technology, 11(4), 64-71.

Nemmich, S., Tilmatine, A., \& Hammadi, N. (2016). Set-point identification of ozone water treatment process. Latin American Applied Research-An international journal, 46(1), 1-6.

Nogales, C. G., Ferrari, P. H., Kantorovich, E. O., \& Lage-Marques, J. L. (2008). Ozone therapy in medicine and dentistry. $J$ Contemp Dent Pract, 9(4), 75-84.

Ong, K. C., Cash, J. N., Zabik, M. J., Siddiq, M., \& Jones, A. L. (1996). Chlorine and ozone washes for pesticide removal from apples and processed apple sauce. Food chemistry, 55(2), 153-160.

Pandiselvam, R., Subhashini, S., Banuu Priya, E. P., Kothakota, A., Ramesh, S. V., \& Shahir, S. (2019). Ozone based food preservation: a promising green technology for enhanced food safety. Ozone: Science \& Engineering, 41(1), 17-34.

Rakovsky, S., Anachkov, M., \& Zaikov, G. (2009). Fields of ozone applications.

Ramdani, N., Lousdad, A., Tilmatine, A., \& Nemmich, S. (2016). Dielectric barrier discharge-based investigation and analysis of wastewater treatment and pollutant removal. Water Science and Technology, 73(12), 2858-2867.

Rice, Rip, G., Ozone Preservation of Foods and Foodstuffs: Literature Review and Current Regulatory Status," Proceedings, (1997). International Ozone Association PanAmerican Conference, Lake Tahoe, Nev, 249-259.

Scott, D. M., \& Lesher, E. C. (1963). Effect of ozone on survival and permeability of Escherichia coli. Journal of bacteriology, 85(3), 567-576. 
Skog, and CL Chu, L. J. (2001). Effect of ozone on qualities of fruits and vegetables in cold storage. Canadian Journal of Plant Science, 81(4), 773-778.

Smilanick, Joseph, L. (2003).Use of ozone in storage and packing facilities. In ashington tree fruit postharvest conference. 1-10.

Taguchi, G., (1987). System of Experimental Designs., Kraus International Publications, New York.

Tuffi, R., Lovino, R., Canese, S., Cafiero, L.M.,Vitali,F. (2012). Effects of exposure to gaseous ozone and negative air ions on control of epiphytic flora and the development of Botrytis cinerea and Penicillium expansum during cold storage of strawberries and tomatoes. Italian Journal of Food Science, 24(2), 102-114.

\section{Acknowledgement}

This study was performed under the framework of 'Projet Impact SocioEconomique' Contract $N^{\circ} 362$ funded by the General Directorate of Algerian Scientific Research (DGRSDT). 